WellBeing International

WBI Studies Repository

10-1997

\title{
Vocal Response of Piglets to Weaning: Effect of Piglet Age
}

Daniel M. Weary

Agriculture and Agri-Food Canada

David Fraser

Agriculture and Agri-Food Canada

Follow this and additional works at: https://www.wellbeingintlstudiesrepository.org/ontoge

Part of the Animal Studies Commons, Developmental Biology Commons, and the Other Animal Sciences Commons

\section{Recommended Citation}

Weary, D. M., \& Fraser, D. (1997). Vocal response of piglets to weaning: effect of piglet age. Applied Animal Behaviour Science, 54(2-3), 153-160.

This material is brought to you for free and open access by WellBeing International. It has been accepted for inclusion by an authorized administrator of the WBI Studies Repository. For more information, please contact wbisr-info@wellbeingintl.org.

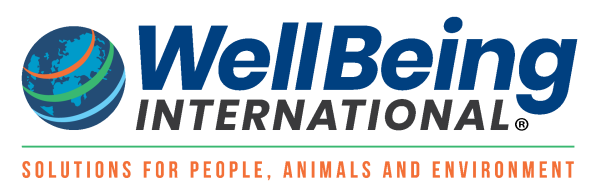




\title{
Vocal Response of Piglets to Weaning: Effect of Piglet Age
}

Daniel M. Weary and David Fraser

Agriculture and Agri-Food Canada

\author{
KEYWORDS \\ pigs, weaning, vocalization, welfare, performance
}

\begin{abstract}
Piglets vocalize a great deal during the first few days after weaning. The aim of this experiment was to determine if the calls given by piglets vary in response to one factor thought to influence post-weaning adaptation: weaning age. In 22 litters, each containing a minimum of 9 piglets, 3 piglets were weaned under identical conditions at 3,4 and 5 weeks of age. Vocalizations and weight gain were monitored for the week after weaning. The number of calls produced by piglets of all three ages declined from an average of 8.2 calls/min per piglet on the day of weaning to only 1.6 calls/min 4 days later. Overall, piglets weaned at younger ages called more $(P<0.001)$ : piglets weaned at 3 weeks produced an average of 3.6 calls/min during the week after weaning, while those weaned at 4 and 5 weeks produced 2.9 and 2.3 calls/min respectively. The average frequency of the calls also fell $(P<0.001)$, from $441 \mathrm{~Hz}$ for piglets weaned at 3 weeks of age to 384 $\mathrm{Hz}$ for those weaned at 5 weeks. These results suggest that vocalizations can be useful for monitoring post-weaning adaptation in piglets.
\end{abstract}

\section{Introduction}

In pigs and peccaries, natural weaning is a gradual process characterized by a decrease in nursing frequency by the mother and an increase in solid food consumption by the young (Newberry and WoodGush, 1985; Jensen and Recén, 1989; Babbitt and Packard, 19901, much as occurs in other mammals (e.g., Thiels et al., 1990). In semi-natural conditions, piglets gradually decrease their intake of milk and increase their intake of solid food, but continue to suckle occasionally until they are 3 months of age or older (Newberry and Wood-Gush, 1985; Jensen and Recén, 1989).

Under commercial conditions, however, natural weaning is rarely allowed to occur. Instead, young and parent are separated at an earlier age (in pigs, typically between 2 and 6 weeks of age) and this early weaning may be a source of distress for both parent and young. Several studies have documented the behaviours associated with early weaning. Fraser (1978) compared piglets weaned at 3 weeks of age with those not yet weaned and found that the newly-weaned piglets were more active, aggressive, and directed more 'belly-nosing' (rooting the ventral service of the body with the snout, as in suckling) towards 
pen-mates. In a similar experiment, Worsaae and Schmidt (1980) found similar behavioural effects as well as increased plasma cortisol concentrations in the weaned piglets. Dybkjær (1992) also found increases in these behaviours when piglets were weaned under more crowded and socially stressful conditions.

Two studies have specifically compared the behavioural response of piglets to weaning at different ages. Metz and Gonyou (19901 weaned piglets at 2 and 4 weeks of age and found that the piglets weaned at 2 weeks tended to be more active and more likely to belly-nose pen-mates during the 7 days after weaning. Bee (1993) weaned piglets at 4 and 6 weeks of age, and again found that younger weaning led to greater activity and more belly-nosing of pen-mates. Early-weaned piglets also show some evidence of immunological compromise (Metz and Gonyou, 19901, and typically have poorer weight gains (or greater weight losses) following weaning (Leibbrandt et al., 1975). Furthermore, the digestive physiology of the piglet matures a great deal between 3 and 5 weeks of age (Cranwell, 19951, such that younger piglets are less able to digest solid feed. In combination, these results suggest that piglets adapt better to weaning at older ages.

Fig. 1. Spectrogram of an 8-s sequence of calls from 4-week old pigs approximately $7 \mathrm{~h}$ after weaning.

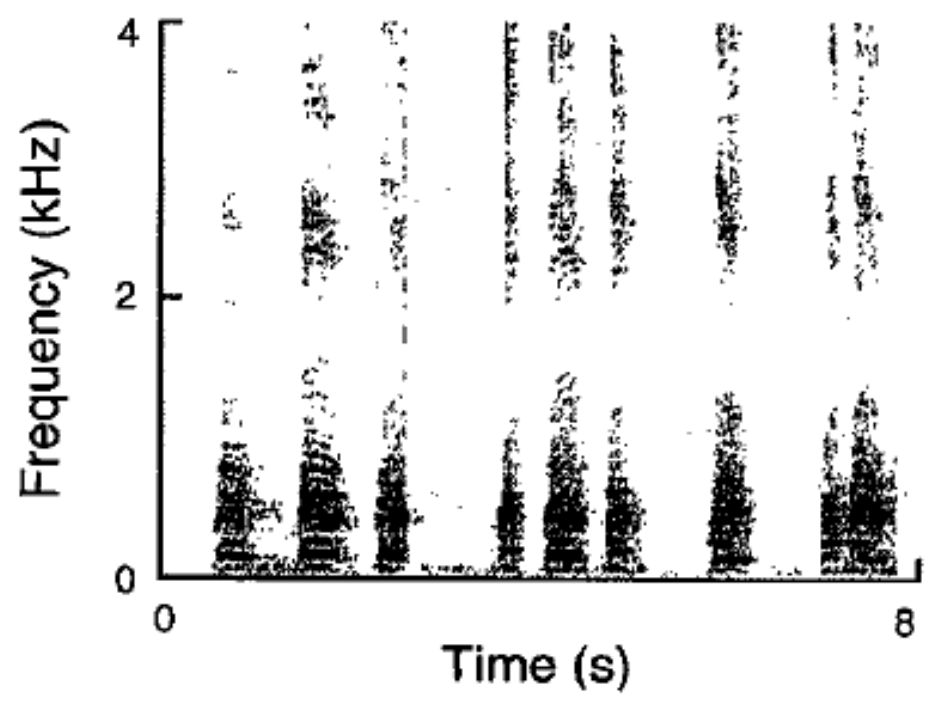

The vocalizations of piglets may be useful in assessing the response of piglets to early weaning (Weary and Fraser, 1995a). Piglets are vocal after weaning (Fig. 1), and piglet vocalizations have been noted in studies of weaning conflict in the wild (Babbitt and Packard, 1990). Our own experiments have shown that piglets that have been temporarily separated from the sow vocalize at a high rate (Fraser, 1975; Weary and Fraser, 1995b), and that sows respond to these calls by calling and approaching the piglet in a manner likely to effect a reunion (Weary et al., 1996). These experiments also show that the calls of isolated piglets vary with the piglets' need for a response by the sow. For example, piglets isolated when mildly food-deprived called more than those that had just fed (Weary and Fraser, 1995b). The aim of the current experiment was to determine if piglet vocalizations at weaning relate to weaning age. If piglets do adapt better to weaning at older ages, we predict that older animals should vocalize less at weaning.

\section{Animals, materials and methods}

The experiment involved 22 litters from a minimum-disease herd, each litter containing a minimum of 9 piglets. Sows and their litters were housed in standard farrowing crates before weaning, and piglets were 
weaned into pens $(1.2 \times 1.2 \mathrm{~m})$ with galvanized steel walls and plasticized, expanded-metal flooring, raised $0.5 \mathrm{~m}$ above the floor of the room. Temperature in the weaning rooms was maintained at $30^{\circ} \mathrm{C}$. Piglets were supplied a complex solid feed (Ralston Purina Baby Boomer Plus) from 10 days of age until 1 week after weaning, at which point the experiment ended and piglets were returned to the herd.

Piglets were weaned at 3,4 or 5 weeks of age. Three piglets were weaned at each age from each litter. Any remaining piglets were weaned at 5 weeks but not used in the experiment. The advantage of this design is that it allows a within-litter test of piglet age, but a disadvantage is that piglets remaining in the litter after 3 and 4 weeks experience a reduced litter size.

Following standard barn procedures all piglets were weaned on Thursdays. Consequently, weaning age varied \& \pm 3 days between litters, but within litters (the basis of our statistical comparisons) age differences were always exactly 1 week. All piglets were weighed at birth and on the Thursday closest to their third week of age, and randomly assigned to the three weaning-age treatments. Piglets and feed were weighed on the day of weaning, the day after weaning (Friday), 4 days after weaning (Monday) and one week after weaning (Thursday). Weaning and all weighing took place between 1100 and $1200 \mathrm{~h}$.

At weaning the group of 3 piglets was moved to a separate weaning room, visually and acoustically isolated from other animals. Vocalizations from the group were monitored for one week after weaning. Calls were recorded during four 7-min periods each day (starting at 1200, 1800, 2400, and $0600 \mathrm{~h}$ ), for a total of 28 recording sessions during the week. Calls were recorded using a Beyer Dynamic MCE86 N(C) microphone (suspended from the ceiling approximately $1 \mathrm{~m}$ above the floor of the pen), a Symetrix SX202 preamplifier and a Sony DTC-59ES digital audio tape recorder controlled by an external timer.

Reliable measures of call features such as frequency and duration were not always possible because of overlap between calls and extraneous noises. The use of plasticized flooring and well-secured penning reduced the mechanical noises resulting from movements of the piglets in the pen, but these could not be eliminated entirely. In order to provide some description of the call features, we measured the duration (ms) of calls and frequency of loudest band in each call $(\mathrm{Hz})$ from a limited sample of recordings using Signal software (Engineering Design, 1991). For this analysis we selected haphazardly 11 of the 22 litters. We selected 10 16-s samples from the recordings made during the first 2 days after weaning, and 10 more from recordings made on the fourth or fifth day after weaning for each litter at each of the 3 ages. Recordings were selected that were free of extraneous noise. A total of 4845 calls were analyzed.

We restricted our primary analysis of vocal response to call counts. The DAT recordings were used to count (by ear) all vocalizations produced by the pen of 3 piglets during each 7-min recording session. We could not reliably distinguish the calls of the 3 different piglets in each group, so the total number of calls produced by all 3 piglets was noted, although very quiet calls may have been masked occasionally by a louder simultaneous call of a pen-mate. A single listener scored the tapes from all 22 litters. To determine the repeatability of these data, a second listener independently scored the 28 recordings of each of 4 haphazardly selected litters. The within-litter correlation between the measures of the two scorers averaged 0.98 .

Calling often varied a great deal between successive recording sessions, presumably because of differences in piglet activity. To reduce the effect of this variation, call rate was averaged for the entire 28 sessions recorded to give a mean call rate for each group of 3 piglets. These group means, together with those for weaning weight, feed intake, and piglet weight gain during the week after weaning, were analyzed using a general linear model (SAS Institute Inc., 1989) including litter (21 df) followed by weaning age $(3,4$ or 5 weeks) as independent variables. Weaning age was considered as a linear effect (with $1 \mathrm{df}$ ), rather than a class effect, because the relationship between age and the four dependent 
variables appeared linear and because the class effect (in preliminary analyses) did not account for significant additional variation after the linear effect was included in the model. As there were 66 observations ( 3 age groups from each of 22 litters) the maximum error $\mathrm{df}$ in an analysis incorporating the litter mean and weaning age was 43, although missing values (due to the occasional missed weight or failed recording session) reduced the error df somewhat in most analyses. The sub-sample of data on call frequency and duration were analyzed using the same model but with only 11 litters.

Fig. 2. Mean ( \pm s.e.m.) call rate (A), weaning weight (B), weight gain $(0$, and feed consumption (D) in relation to weaning age. Measures of call rate, weight gain and feed consumption are averages over the week after weaning. Call rate and feed consumption were measured for the pen of 3 piglets but the means are expressed per piglet.
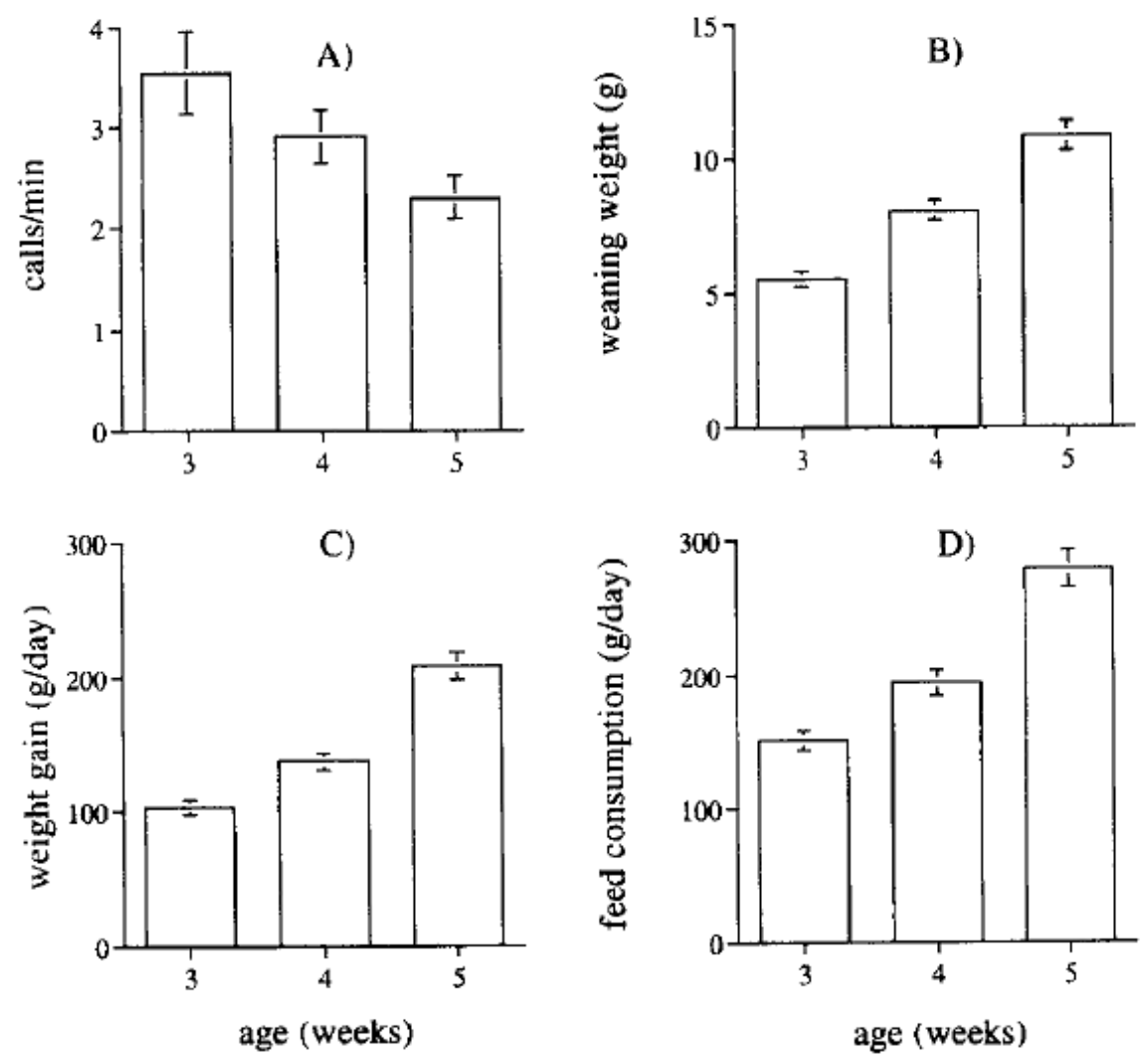

To test if weight gain and feed intake varied in relation to weaning age even after correcting for weaning weight, we re-ran our analyses of weight gain and feed intake testing the effect of weaning age after taking the litter term and weaning weight into account as independent variables. In order to determine if variation in performance within an age class affected calling, we re-ran the analysis of call rate including each of the performance measures (in 3 separate models) as a final variable after litter and age. We also tested the relative effect of weight gain (and feed intake in a separate model) on call rate by including gain after litter, age and weaning weight in our general linear model.

\section{Results}

There was a rapid reduction in call rate during the first few days after weaning. Call rate averaged 8.2 calls/min per piglet on the day of weaning. Four days later call rate had declined to only $1.6 \mathrm{calls} / \mathrm{min}$ and showed little further decline during the rest of the week. 
Piglets weaned at older ages called at lower rates during the week after weaning: those weaned at 3 weeks of age produced, on average, $3.6 \mathrm{calls} / \mathrm{min}$ as compared to 2.9 and $2.3 \mathrm{calls} / \mathrm{min}$ for those weaned at 4 and 5 weeks of age (Fig. $2 \mathrm{~A} ; F=13.07$, df $=1,32, P<0.001$ ). There was also a strong positive relationship between weaning age and each of the performance measures (weaning weight, Fig. 2B, $F=$ 357.13, df = 1, 43, $P<0.001$; weight gain, Fig. 2C, $F=37.81$, df $=1,43, P<0.001$; feed intake, Fig. 2D, $F=39.68, \mathrm{df}=1,29, P<0.001)$. However, there was no significant effect of age on weight gain or feed intake after correcting for weaning weight. Within age classes, variation in weaning weight, weight gain and feed intake, as well as weight gain and feed intake relative to weaning weight, all had no significant relation with call rate.

Our analysis of the structure of the calls, using recordings from 11 of the 22 litters, showed similar effects to call rate. The structure of calls changed over the first few days after weaning. On the first two days after weaning, calls had a mean ( \pm s.e.m.) frequency of $418 \pm 7 \mathrm{~Hz}$ and duration of $405 \pm 15 \mathrm{~ms}$. Four to five days after weaning calls were somewhat lower in frequency (403 $\pm 7 \mathrm{~Hz}$ ) and shorter in duration (283 \& $20 \mathrm{~ms}$ ). The call frequency also declined with weaning age, from an average of $441 \pm 7 \mathrm{~Hz}$ for piglets weaned at 3 weeks of age to $405 \pm 9 \mathrm{~Hz}$ and $384 \pm 7 \mathrm{~Hz}$ for those weaned at 4 and 5 weeks of age $(F=$ 23.99, $\mathrm{df}=1,21, P<0.001)$. There was no significant decline with age in call duration.

\section{Discussion}

In our experience, piglets rarely vocalize before weaning except in specific contexts such as when isolated, fighting for teats or when trapped beneath the sow. In contrast, this study showed a high rate of calling after weaning. Call rate was highest on the day of weaning and then slowly declined during the remainder of the week. This pattern contrasts with that of some other behaviours associated with weaning. Belly-nosing, for example, is not normally seen in the first few days after weaning, but rather develops days later (Fraser, 1978; Blackshaw, 1981; Metz and Gonyou, 1990).

In a number of studies we have found that the calls of isolated piglets are influenced by the piglets' condition. Piglets at 10 days of age call more during 12 min of separation from the sow and litter if they are small and slow growing, have just missed a milk ejection, or are isolated in a relatively cool enclosure (Weary and Fraser, 1995b; Weary et al., 1997). Although the piglets in the present study were older and we recorded calls over a much longer period, the calls are produced in similar situations (i.e., when piglets are separated from the sow) and they sound similar to the calls recorded in the earlier studies. The calls recorded in the present study were on average ( \pm S.D.) slightly longer (346 $\pm 118 \mathrm{vs} .272 \pm 221 \mathrm{~ms}$ ) and lower in frequency of the loudest band in the call $(410 \pm 41$ vs. $435 \pm 172 \mathrm{~Hz})$ than those recorded from the younger isolated piglets, and included fewer of the high-pitched squeals commonly interspersed in the calling of younger piglets in total isolation.

Call rate and the mean frequency of the calls during the week after weaning were negatively related to piglet age. These results are consistent with the hypothesis that vocalizations are an indicator of postweaning adaptation, but this conclusion is contingent upon the assumption that weaning is more difficult for younger piglets. The studies cited in the introduction support this assumption, as do our own results showing that the older piglets were heavier, gained more weight, and consumed more solid feed. Less supportive of a general relationship is that calling did not relate to gains or intake after correcting for weaning weight, and that no significant relationship was found between calling and performance within each of the three age groups.

One weakness inherent in all age comparisons is the difficulty in distinguishing general developmental effects from the more specific effects of interest. Thus in the current experiment it is possible that our results reflect a general decline in vocalizations with age, and not an easier transition to weaning for the 
older animals. For example, the fact that older piglets produced lower frequency calls may have been due to the larger size of these animals. Comparative work in other species has shown that animals with more massive vocal structures tend to produce lower frequency calls (Ryan and Brenowitz, 1984). The available evidence, however, argues against a general decline in call rate with age. Little experimental work has been done on the energetic costs of calling (Horn et al., 19951, but theory would indicate that signalling is less costly for larger animals, and thus these animals could be expected to call more in response to the same conditions (Johnstone and Grafen, 19931. Consistent with this prediction, two experiments have shown that calling in response to restraint increases with the piglet age. White et al. (1995) found that piglets restrained at 24 days of age produced calls that were higher in frequency than piglets restrained at 8 days or 16 days, and a similar experiment in our laboratory showed that older piglets call more and produce more high frequency calls (A.A. Taylor, unpublished data).

In conclusion, we suggest that the higher call rate of younger piglets in this experiment reflects a more difficult transition to weaning for these animals, but caution readers that further tests are necessary. Particularly instructive would be tests on piglets weaned at the same age but into different post-weaning environments.

\section{Acknowledgements}

We are especially grateful to Sue Leffler for her many hours of tape analysis and to Brian Thompson for his help with the statistical analysis. We also thank Mike Appleby, Ed Pajor, Allison Taylor and Jeff Rushen for their comments on early drafts of this manuscript, and the staff of our research barn for their help throughout the study.

\section{References}

Babbitt, K.J., Packard. J.M.. 1990. Parent-offspring conflict relative to phase of lactation. Anim. Behav. 40, 165-773.

Blackshaw, J.K.. 1981. Some behavioural deviations in weaned domestic pigs: persistent inguinal nose thrusting, and tail and ear biting. Anim. Prod. 33, 325-332.

Bee, K.. 1993. The effect of age at weaning and post-weaning environment on the behaviour of pigs. Acta Agric. Stand., Sect. A., Animal Sci. 43, 173-180.

Cranwell, P.D.. 1995. Development of the neonatal gut and enzyme systems. In: Varley, M. (Ed.), The Neonatal Pig: Development and Survival. CAB International, Wallingford, UK, 99- 154.

Dybkjær, L.. 1992. The identification of behavioural indicators of 'stress' in early weaned piglets. Appl. Anim. Behav. Sci. 35, 135-147.

Engineering Design, 1991. Signal: User’s Manual. Engineering Design, Belmont, Massachusetts.

Fraser, D.. 1975. Vocalizations of isolated piglets. I. Sources of variation and relationships among measures. Appl. Anim. Ethol. 1, 387-394.

Fraser, D.. 1978. Observations on the behavioural development of suckling and early-weaned piglets during the first six weeks after birth. Anim. Behav. 26, 22-30. 
Horn, A.G., Leonard, M.L.. Weary, D.M., 1995. Oxygen consumption during crowing by roosters: talk is cheap. Anim. Behav. 50, 1171-1175.

Jensen, P., Recén, B., 1989. When to wean-observations from free-ranging domestic pigs. Appl. Anim. Behav. Sci. 23. 49-60.

Johnstone, R.A.. Grafen, A., 1993. Dishonesty and the handicap principle. Anim. Behav. 46, 759-764.

Leibbrandt, V.D., Ewan, R.C.. Speer, V.C., Zimmerman, D.R., 1975. Effect of weaning and weaning age on baby pig performance. J. Anim. Sci. 4, 1077-1080.

Metz, J.H.M., Gonyou, H.W., 1990. Effect of age and housing conditions on the behavioural and haemolytic reaction of piglets to weaning. Appl. Anim. Behav. Sci. 27, 299-309.

Newberry, R.C., Wood-Gush, D.G.M., 1985. The suckling behaviour of domestic pigs in a semi-natural environment. Behaviour 95, 11-25.

Ryan, M.J., Brenowitz, E.A., 1984. The role of body size, phylogeny, and ambient noise in the evolution of bird song. Am. Nat. 126, 87-100.

SAS Institute Inc., 1989. SAS/STAT User's Guide, Version 6, 4th edn., Volume 2. SAS Institute, Cary, NC.

Thiels, E., Alberts, J.R., Cramer, C.P., 1990. Weaning in rats: II. Pup behavior patterns. Devel. Psychobiol. 23. 495-510.

Weary, D.M., Fraser, D., 1995a. Signalling need: costly signals and animal welfare assessment. Appl. Anim. Behav. Sci. 44, 139-157.

Weary, D.M., Fraser, D., 1995b. Calling by domestic piglets: reliable signals of need?. Anim. Behav. 50, 1047-1055.

Weary, D.M., Lawson, G., Thompson, B.K., 1996. Sows show stronger responses to isolation calls of piglets associated with greater levels of piglet need. Anim. Behav. 52, 1247-1253.

Weary, D.M., Ross, S.K., Fraser, D., 1997. Piglet vocalizations and welfare assessment: cold stress increases calling by isolated piglets. Appl. Anim. Behav. Sci. 53, 249-257.

White, R.G., DeShazer, J.A., Tressler, C.J., Borcher, G.M., Davey, S., Waninge, A., Parkhurst, A.M., Milanuk, M.J., Clemens, E.T., 1995. Vocalization and physiological response of pigs during castration with or without a local anaesthetic. J. Anim. Sci. 73, 381-386.

Worsaae. H.. Schmidt, M., 1980. Plasma cortisol and behaviour in early weaned piglets. Acta Vet. Stand. 21, 64-657. 